\title{
(10) \\ Determination of Hydrogen Diffusion Parameters of Ferritic Steel from Electrochemical Permeation Measurement under Tensile Loads
}

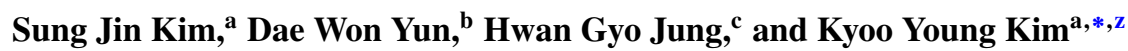 \\ ${ }^{a}$ GIFT, Pohang University of Science and Technology (POSTECH), Nam-Gu, Pohang 790-784, Korea \\ ${ }^{b}$ Korea Institute of Materials Science (KIMS), Seongsan-gu, Changwon 642-831, Korea \\ ${ }^{c}$ POSCO Technical Research Laboratories, Geidong-Dong, Pohang 790-704, Korea
}

\begin{abstract}
The hydrogen permeation experiment, performed with a stepwise permeation sequence involving " $1{ }^{\text {st }}$ permeation-desorption- $2^{\text {nd }}$ permeation under loading, demonstrates that fine blister cracks are frequently observed on the steel surface in hydrogen charging side after the $2^{\text {nd }}$ permeation under the load over $95 \%$ of yield strength of the steel. To accommodate the experimental phenomena under the loading conditions, a numerical model is developed for determination of hydrogen diffusion parameters of the sour-resistant ferritic steel evaluated under tensile stress in plastic ranges. To solve the modified diffusion equation, a numerical finite difference method (FDM) is employed. The diffusion parameters determined by curve-fitting with the newly proposed diffusion equation indicates that, with the transition of mechanical domain from local-plasticity to generalized-plasticity, a big increase in the crack formation rate and hydrogen capture rate per irreversible trap are observed. It suggests that the transition probability for hydrogen transport from interstitial lattice site to irreversible trap site increases with the stress level.

(C) The Author(s) 2014. Published by ECS. This is an open access article distributed under the terms of the Creative Commons Attribution 4.0 License (CC BY, http://creativecommons.org/licenses/by/4.0/), which permits unrestricted reuse of the work in any medium, provided the original work is properly cited. [DOI: $10.1149 / 2.1021412 \mathrm{jes}$ ] All rights reserved.
\end{abstract}

Manuscript submitted July 21, 2014; revised manuscript received September 2, 2014. Published September 12, 2014.

The high-strength ferritic steels used in the petrochemical industry suffer frequently from hydrogen assisted cracking (HAC) problem when they are used in a sour environment containing $\mathrm{H}_{2} \mathrm{~S}^{1-3}$ Atomic hydrogens which result from the reduction of $\mathrm{H}^{+}$ions dissociated from $\mathrm{H}_{2} \mathrm{~S}$ become the hydrogen molecule by the recombination reaction $\left(\mathrm{H}+\mathrm{H} \rightarrow \mathrm{H}_{2}\right)$. Since $\mathrm{H}_{2} \mathrm{~S}$ dissolved in aqueous environment suppresses this recombination reaction, the hydrogen atoms are easily adsorbed on the steel surface and diffuse into the steel matrix. ${ }^{4,5}$ The hydrogen atoms absorbed in the steel are reversibly or irreversibly trapped at various metallurgical defects in the steel, often resulting in the HAC failure. ${ }^{2,6}$ With the depletion of high quality oil and gas, the $\mathrm{HAC}$ failure may become serious engineering problem for the highstrength steel pipes transporting and/or processing the low quality oil and gas containing a large amount of $\mathrm{H}_{2} \mathrm{~S}$.

The HAC problem can be classified into two categories depending on the source of hydrogen and stress level; one is hydrogen induced cracking (HIC) occurring under no applied stress ${ }^{2,6}$ and the other is sulphide stress cracking (SSC) occurring under applied tensile stress or residual stress. ${ }^{7,8}$ In order to understand clearly HAC failure of the steels, the combined effect of hydrogen and applied stress should be evaluated together. A number of considerable efforts have been directed to evaluate the influence of applied tensile stress on the hydrogen diffusion behavior in the steel employing the electrochemical permeation technique..$^{9-12}$ It has been generally accepted that the applied tensile stress in elastic range has no significant effect on the hydrogen diffusivity but increases the steady-state permeation flux due to the elastically expanded lattice. ${ }^{10,12,13}$ On the other hand, a significant decrease in the permeation current has been observed in body centered cubic (BCC)-based materials under the tensile stress in plastic range and it has been attributed to the enhanced hydrogen trapping by newly generated dislocation. ${ }^{9,10}$ Although failure of the palladium (Pd) coating under the high tensile stress condition has raised controversy on the reliability of the permeation data, our previous works have demonstrated clearly that the tensile stress in plastic range results in a considerably slower permeation rate by excluding other side effects such as the reduced rate of hydrogen oxidation caused by disruption of the Pd layer. ${ }^{14-16}$ When the stress level becomes close to the yield strength (YS), however, the effect of tensile stress on the hydrogen permeation does not follow the general effect of elastic stress which

\footnotetext{
*Electrochemical Society Active Member.
}

${ }^{\mathrm{z} E}$-mail: kykim@postech.ac.kr induces the increase in permeation flux due to the lattice expansion, but often results decrease in the permeation flux. ${ }^{17}$ A slight decrease in the apparent diffusivity of hydrogen is also observed. Furthermore, surface blisters and internal cracks acting as hydrogen trapping sites are newly created during the permeation test. This means that the trap density for hydrogen atoms does not keep constant but change dynamically during the test. Therefore, under the stress condition, it is difficult to follow the conventional analysis method for hydrogen transport in the steel.

For the fundamental understanding of hydrogen transport in the steel, numerous theoretical models describing the hydrogen diffusion and trapping phenomena in the steel membrane have been proposed. In 1963, McNabb and Foster have presented the hydrogen diffusion with trapping model, assuming that irreversible trapping sites are not present in the matrix. ${ }^{18}$ Oriani et al. ${ }^{19}$ have developed a solution of McNabb and Foster's model for the case of rapid equilibrium between the trapping and normal diffusion sites. Iino et al. ${ }^{20}$ have proposed a diffusion model, considering the situation of irreversible trapping. Leblond and Dubois ${ }^{21}$ have also considered the combined effect of reversible and irreversible trapping effect, but only for low fractional occupancy of reversible trapping sites. The only known analytic solution for the McNabb and Foster's equation is the one proposed by Oriani et al. ${ }^{19}$ under the assumption of local equilibrium and low fraction of occupied traps. Turnbull et al. ${ }^{22}$ have conducted a mathematical analysis for hydrogen diffusion in the steel and proposed a numerical solution even in the presence of irreversible traps with a finite trapping rate, not in local equilibrium. On the contrary, Castaño-Rivera et al. ${ }^{23}$ have developed a numerical finite difference method (FDM) to solve the diffusion equation under the case of local equilibrium and high fraction of occupied traps with high binding energy but not irreversible. These hydrogen diffusion models have contributed much to understand the mechanism of HIC failure which is considered as one of the major technical issues for development of high-strength steels. However, there has been no accurate model and equation which can be applied for the real engineering situation where the steel is subjected simultaneously to the hydrogen charging and loading. For this reason, the study on SSC phenomena has not been progressed any further. Especially, under the high level of tensile stress which causes the local plasticity or plastic deformation in the steel, the conventional diffusion equations cannot simulate adequately the experimental results. In order to understand clearly the influence of the tensile stress in plastic range on the hydrogen diffusion process which changes dynamically depending on the trapping property of various types of 
defects, a numerical model should be developed in accordance with the experimental result. Since the interpretation of hydrogen permeation data of the high-strength steel is limited to condition of the stress level only under elastic range, in this study, a numerical modeling is designed to extend to the interpretation of permeation data obtained even under plastic stress range. Moreover, FDM is used to solve the newly modified diffusion equation applicable for determination of various diffusion parameters from the hydrogen permeation data obtained under the stress conditions. Consequently, the values of various hydrogen diffusion parameters are determined by curve-fitting with the modified diffusion equation to the experimental data.

\section{Experimental}

Test material. - The test material used in this study is a sour resistant ferritic steel equivalent to ASTM A516 grade pressure vessel steel. The steel was normalized by heating to $910^{\circ} \mathrm{C}$ for 30 minutes and subsequently cooled to room temperature at a rate of around $0.67^{\circ} \mathrm{C} \mathrm{s}^{-1}$.

Hydrogen induced cracking and sulphide stress cracking test.- In order to evaluate the HIC susceptibility of the tested steel, HIC test was initially performed in reference to National Association of Corrosion Engineers (NACE) TM0284 standard method. ${ }^{24}$ After the test, HIC occurrence level of the tested steel was determined by analyzing with an ultrasonic detector. For the specimen failed by hydrogen cracking, a fresh fracture surface was obtained and the crack initiation sites were analysed using field emission-scanning electron microscopy (FE-SEM) and energy dispersive spectroscopy (EDS). SSC test was also conducted by the constant load test (CLT) for 720 hours as specified by NACE TM0177A standard. ${ }^{25}$ The SSC sensitivity of the steel was determined as the maximum sustaining load $\left(\sigma_{\text {th }}\right)$ without failure for 720 hours. To clarify the SSC failure mode, four-point bent beam test (BBT) in reference to ASTM G39 standard ${ }^{26}$ was additionally performed.

Electrochemical permeation test.- The sheet-type tensile specimen, with $1 \mathrm{~mm}$ thickness, was then machined from the center region of the steel plate and the detailed specification of the specimen can be identified in our previous work. ${ }^{15}$ The radius of the circular area exposed to the electrolyte was $10 \mathrm{~mm}$ and the membrane thickness was $1 \mathrm{~mm}$, so that the ratio of radius to the membrane thickness met the requirement specified in ISO 17081 standard method. Although there has been a controversy as to whether the thin steel membrane can be controlled by the volume diffusion through the steel or by the surface reaction, our preliminary test result has revealed that the steel membrane under applied cathodic current density of $2 \mathrm{~mA} \mathrm{~cm}^{-2}$ is controlled by the volume diffusion. In order to clarify this fact, a permeation experiment has been carried out using the steel membrane with various thicknesses in the range from $0.5 \mathrm{~mm}$ to $2 \mathrm{~mm}$. It has been verified that there is an inversely proportional relationship between the permeation flux and sample thickness, which is in good agreement with the Fick's law of diffusion. It has also been found that there is a very slight difference in the apparent diffusivity among the steels with various thicknesses in the range from $0.8 \mathrm{~mm}$ to $2 \mathrm{~mm}$, suggesting that, under the given hydrogen charging condition, the steel membrane with thickness over $0.8 \mathrm{~mm}$ can be controlled by the volume diffusion. A similar experimental result has been previously reported by Park et al. ${ }^{6}$ They have found that there is little difference in the diffusivity when the specimen thickness exceeded at least $1 \mathrm{~mm}$ under cathodic charging condition. Frappart et al. ${ }^{17}$ and Zakroczymski ${ }^{27}$ have also conducted the permeation test using the steel membrane with $1 \mathrm{~mm}$ thickness under cathodic charging condition, and valuable information regarding hydrogen diffusion behavior has been reported. Considering our preliminary test results and previous study conducted by other researchers, it can be considered that the dimension of steel sample used in the present study is sufficient to achieve the volume controlled diffusion and to ignore the contribution of surface reaction. This implies that, under the given hydrogen charging condition, the interfacial reaction associated with hydrogen reduction on the steel surface is fast enough to keep the sub-surface hydrogen concentration at a constant value $\left(C_{0}\right)$. It results in the inversely proportional relationship between the permeation flux and sample thickness. In this case, the volume diffusion through the steel sample used in this study can be the rate determining step in the diffusion kinetics.

Fig. 1 shows the hydrogen permeation test cell equipped with a constant load testing device and a schematic illustration of the permeation cell applicable under loading condition.

The prepared steel membrane was initially installed in a constant load test (CLT) frame and the designed Ni-plating cell was then assembled with the steel membrane in the hydrogen detection side. The thin Ni film, with $100 \mathrm{~nm}$ thickness, was electrochemically deposited to the steel surface using the prepared coating bath (a mixture of $240 \mathrm{~g}$ $1^{-1}$ of $\mathrm{NiSO}_{4} \cdot 6 \mathrm{H}_{2} \mathrm{O}, 30 \mathrm{~g} \mathrm{l}^{-1}$ of $\mathrm{NiCl}_{2} \cdot 6 \mathrm{H}_{2} \mathrm{O}$ and $30 \mathrm{~g} \mathrm{l}^{-1}$ of $\mathrm{H}_{3} \mathrm{BO}_{3}$ in distilled water). A galvanostatic current density of $2.5 \mathrm{~mA} \mathrm{~cm}^{-2}$ was cathodically applied for 3 minutes. After the electroplating, a modified Devanathan cell was then assembled with the steel membrane. The detection side cell was filled with $0.1 \mathrm{M} \mathrm{NaOH}$ solution purged with argon (Ar) gas. The Ni-plated surface exposed to the solution was maintained at a potential of $250 \mathrm{mV}_{\mathrm{SCE}}$, at which the dominant reaction was oxidation of hydrogen atoms which diffused through the steel membrane. Once the background current reached a steady-state
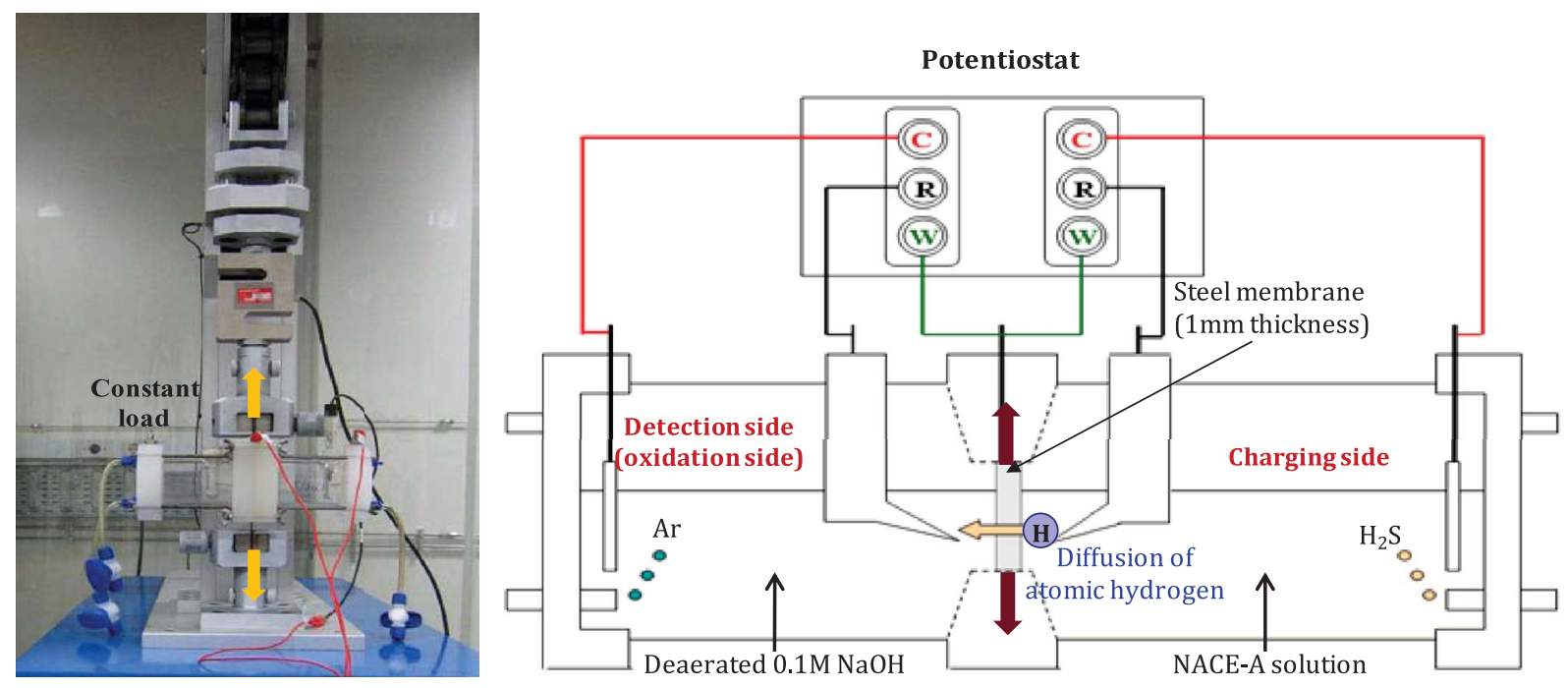

Figure 1. A modified electrochemical permeation cell equipped with a constant load testing device, and schematic illustration of the permeation cell. 


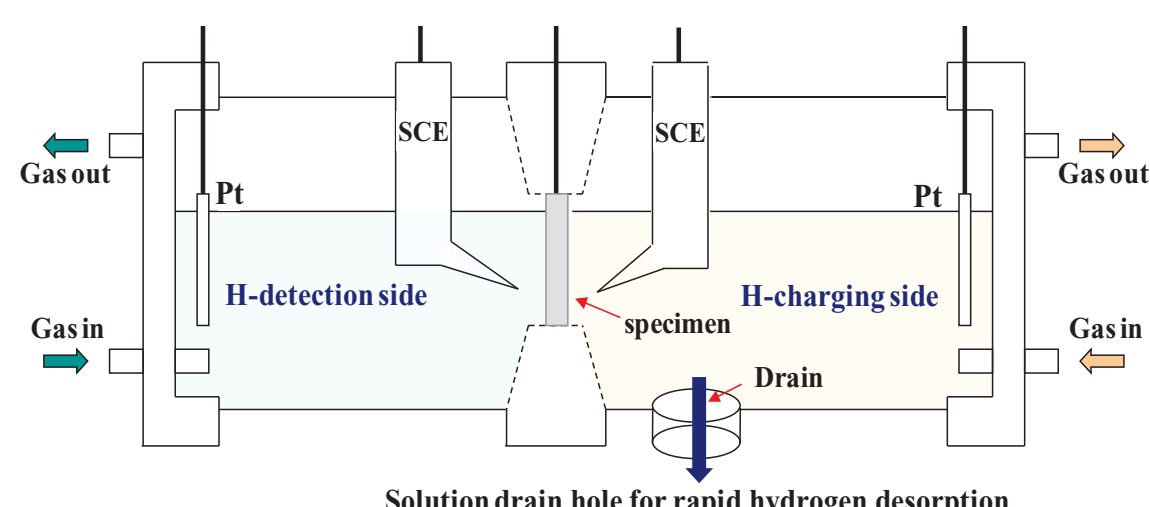

Figure 2. Electrochemical permeation cell specially designed for desorption process. and became stabilized, the $\mathrm{H}_{2} \mathrm{~S}$-saturated NACE TM0284-96 ${ }^{24}$ solution chosen as the hydrogen charging solution was poured into the charging side of the cell. The detailed information of the test procedure except for the Ni- coating can also be referred to our previous work. ${ }^{14}$

In this study, particularly, to measure the irreversibly trapped hydrogen content in the steel, the stepwise sequence involving " $1{ }^{\text {st }}$ permeation-desorption- $2^{\text {nd }}$ permeation" was employed in the permeation test. When the $1^{\text {st }}$ permeation current reaches a steady-state, the hydrogen charging was stopped. Right at the moment the current started to drop, the charging solution was quickly released from the charging cell in just a few seconds and the specimen surface was cleaned by ethanol. In order to perform the former desorption procedure without difficulty, a large circular drain depicted in Fig. 2 was made at the bottom of the charging cell. This is an important step in a sense that the procedure makes it possible to prevent the specimen surface from corrosion process and to ensure that any corrosion products acting as barrier against the hydrogen diffusion are not formed on the surface. Then, the desorption step was maintained until the start of $2^{\text {nd }}$ permeation. When the permeation current in the desorption step reached the background current level, meaning that the diffusible hydrogen atoms were completely removed from the steel, the $2^{\text {nd }}$ permeation test was subsequently conducted on the steel.

\section{Results and Discussion}

HIC resistance and fracture surface analysis. - Fig. 3 shows the typical HIC occurrence level of the steel which was detected ultrasonically after the HIC test. It is known that some cracks are detected in the steel with the average CLR value being 22.73. Fig. 4 presents the HIC fracture surface of the steel, which was obtained by a specially designed mechanical process after crack detection using ultrasonic detector (UT). It is found that the cracks primarily nucleated at the enlarged $\mathrm{Ti}-\mathrm{Nb}(\mathrm{C}, \mathrm{N})$ and $\mathrm{Al}-\mathrm{Ca}-\mathrm{Mg}-\mathrm{O}$ cluster with size over 3 4 $\mu \mathrm{m}$. Although these experimental results provide useful information about the HIC susceptibility of the tested steel, it is not possible to understand clearly the hydrogen diffusion with dynamic trapping behavior in the steel under plastic loading condition. The exact permeation

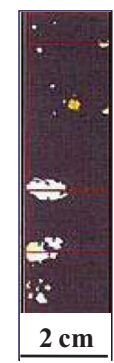

CLR: 22.73

Figure 3. HIC occurrence level with CLR value analysed by ultrasonic detector. behavior and its quantitative analysis are discussed in the following section.

SSC resistance and fracture surface analysis.- SSC resistance of the tested steel is evaluated in terms of the threshold stress $\left(\sigma_{t h}\right)$ and it is found that the $\sigma_{\text {th }}$ of the steel is $82 \%$ of YS. Fig. 5a and $5 \mathrm{~b}$ present the fracture surface obtained after the CLT and crosssectional morphology obtained after the BBT, respectively. The typical hydrogen induced blister cracks (HIBC) and stepwise cracking shown in Fig. 5a and 5b, respectively, indicate that the failure mode for the steel is type I SSC which is generally termed as the stress-oriented hydrogen induced cracking (SOHIC). ${ }^{28}$ As reported previously by Kim et al., ${ }^{35}$ the HIBC develops parallel to the loading axis and it is mainly nucleated at the large size of inclusion or precipitate like the case of the HIC.

Hydrogen permeation behavior under tensile stress conditions.Fig. 6 shows the typical permeation current density of the steel under no load, obtained by the stepwise sequence of " 1 st permeationdesorption- $2^{\text {nd }}$ permeation." In order to validate the permeation data, a $3^{\text {rd }}$ permeation was additionally conducted and the transient is also found in the figure. Since all of the irreversible traps are occupied during the $1^{\text {st }}$ permeation, hydrogen atoms only in the lattice and reversible traps are considered in the $2^{\text {nd }}$ and $3^{\text {rd }}$ permeation under no load. It leads to faster diffusion at an early stage in the $2^{\text {nd }}$ and $3^{\text {rd }}$ permeation and the time to reach the steady-state current density $\left(j_{s s}\right)$ becomes shorter. As expected, the $3^{\text {rd }}$ permeation exhibits a similar trend to the $2^{\text {nd }}$ permeation, which is due to the fact that both transients are affected only by reversible trap site unlike the case of the $1^{\text {st }}$ permeation involving both reversible and irreversible trapping phenomena.

In order to investigate the effect of tensile stress, the tensile stress in three mechanical domains (generalized elasticity: $80 \%$ YS, local plasticity: $95 \%$ YS and generalized plasticity: $120 \%$ YS) was applied to the specimen right before the $2^{\text {nd }}$ permeation. For better understanding of the permeation behavior, $1^{\text {st }}$ and $2^{\text {nd }}$ permeation curves under load and no load are overlapped and they are presented in Fig. 7. As for the shape of the $1^{\text {st }}$ permeation transient, it can be found that the present permeation transients are different as that of stainless steel obtained by Turnbull (i.e. higher breakthrough time and a shift of the curve to higher time values in the presence of irreversible trapping). Based on a number of permeation test results reported by numerous researchers, it can be known that the shape of the $1^{\text {st }}$ permeation transient can be greatly dependent upon steel type, chemical composition, level of plastic deformation and microstructure. It has been reported that the break through time in the $1^{\text {st }}$ permeation of stainless steels or high alloy steels (stainless steel, ${ }^{22,30,31,32} \mathrm{Cr}$-Mo steel, ${ }^{9,33}$ high carbon steel, ${ }^{17,34}$ TRIP steel ${ }^{16}$ ) is comparatively longer than that of low alloy low carbon steels (pure iron, ${ }^{10,27,35,36}$ low carbon ferritic steel ${ }^{6,34,37}$ ). Little difference in the break through times between $1^{\text {st }}$ and $2^{\text {nd }}$ transient is frequently observed in the low carbon ferritic steel. According to the consecutive permeation test result obtained by Chan 


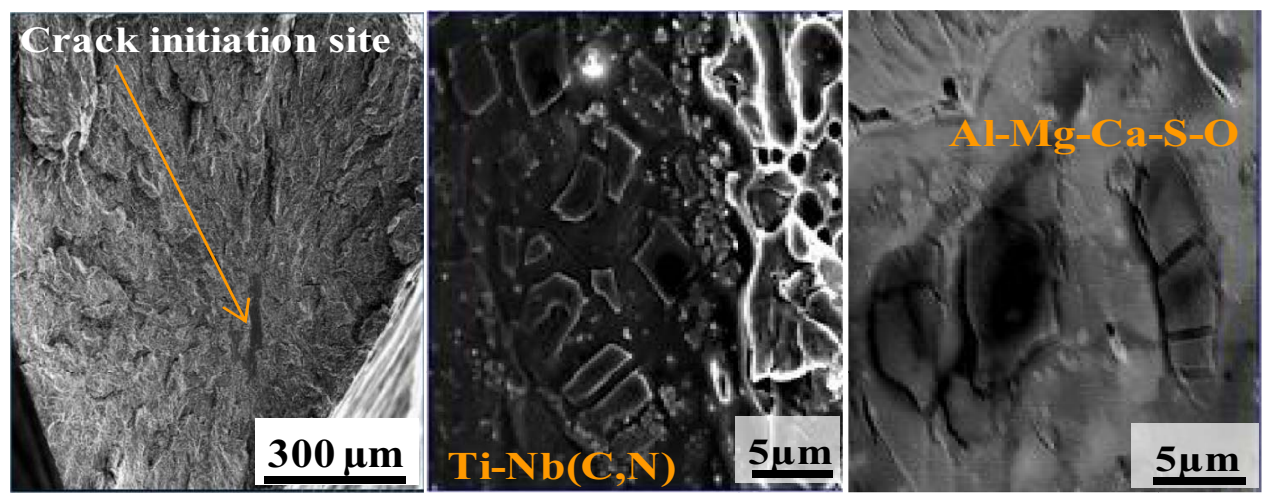

Figure 4. HIC fracture surface of the tested steel, which was obtained by a specially designed mechanical process after crack analysis by using ultrasonic detector.

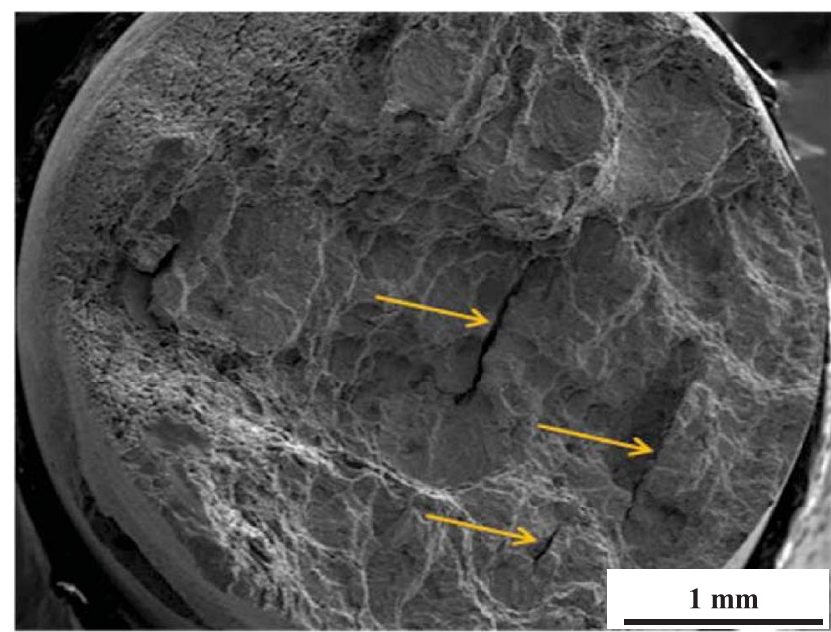

(a)

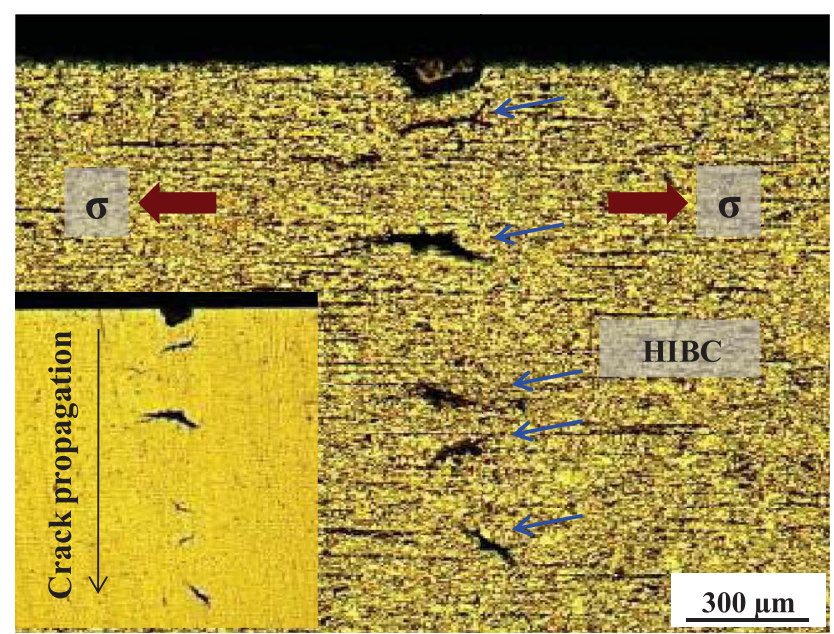

(b)

Figure 5. (a) SSC fracture surfaces of the tested steel obtained by CLT, and (b) Cross-sectional morphology of the tested steel obtained by BBT.

et al., ${ }^{34}$ the trends showing a sharp increase in both $1^{\text {st }}$ and $2^{\text {nd }}$ transients are more significant with a decrease in carbon content and the fraction of retained austenite in the steel.

From the two consecutive permeation transients $\left(1^{\text {st }}\right.$ and $2^{\text {nd }}$ permeation under no load), it is possible to estimate an order of magnitude of irreversible trapping since the area between $1^{\text {st }}$ and $2^{\text {nd }}$ permeation

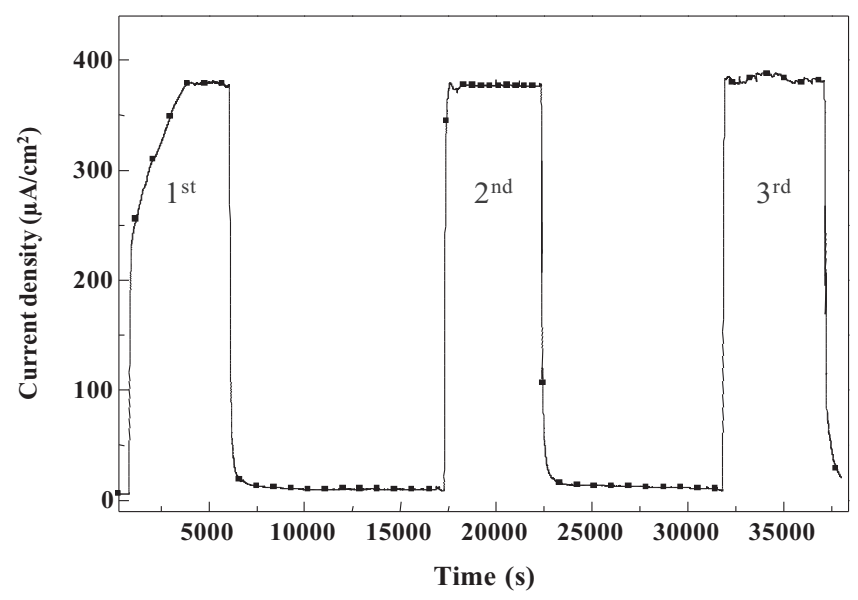

Figure 6. Hydrogen permeation curve of the tested steel, obtained by the stepwise sequence of $1^{\text {st }}$ permeation-desorption- $2^{\text {nd }}$ permeation-desorption$3^{\text {rd }}$ permeation. curves provides an approximate estimation of irreversible trapping phenomenon. ${ }^{38}$ A rough estimation of irreversibly trapped hydrogen content $\left(C_{i r r}=18.6 \mathrm{~mol} \mathrm{~m}^{-3}\right)$ in the tested steel can be calculated

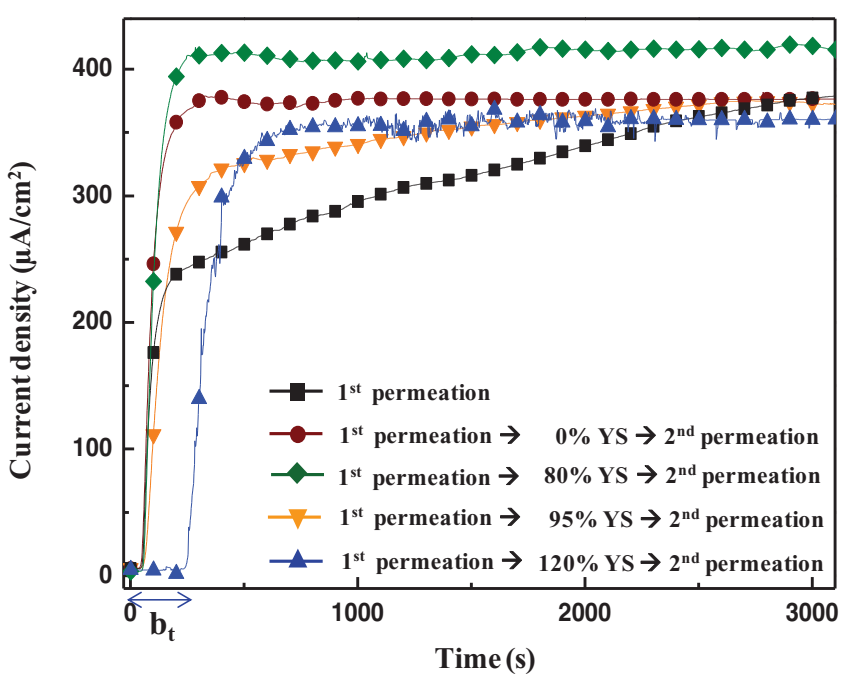

Figure 7. Plot of the $2^{\text {nd }}$ permeation curves overlapping with the $1^{\text {st }}$ permeation curves under load levels. 
from the following equation.

$$
\begin{aligned}
C_{i r r} & =\frac{\Delta Q}{F \cdot L \cdot A}, \frac{\Delta Q}{A} \\
& =\int\left\{j\left(2^{\text {nd }} \text { permeation }\right)-j\left(1^{\text {st }} \text { permeation }\right)\right\} d t
\end{aligned}
$$

where $Q$ is charge, $F$ is the Faraday's constant, and $A$ and $L$ are the exposed surface area and thickness of the steel membrane, respectively.

The value of $C_{i r r}$ is mainly associated with the size, shape and fraction of inclusion and precipitate contained in the tested steel since the interface between the inclusion and precipitate and the steel matrix acts as the irreversible trap site for hydrogen atoms. ${ }^{39,40}$ The application of hydrogen microprint technique (HMT) and thermal desorption spectroscopy (TDS) has made it possible to prove the trapping phenomenon. ${ }^{41,42}$ Especially, Otsuka et al. ${ }^{41}$ and Yamada et al. ${ }^{42}$ have performed the HMT under loading condition and it has been clearly demonstrated that the hydrogen atoms are preferentially trapped at such interfaces.

Under a load of $80 \%$ YS of the steel, a little increase in $j_{s s}$ is clearly identified in the steel. Since the stress level is within generalizedelastic range, the increase in permeation current density may be attributed to the elastic expansion of lattice. Some researchers have also reported similar results. ${ }^{10,12,13}$ When the steel is subjected to a load of 95\% YS, however, it is interesting to see the fact that the increase in permeation current density due to the lattice expansion is not observed. Since the stress condition can generate the local plasticity in the steel, the time to reach the $j_{s s}$ becomes longer, which is not expected for the $2^{\text {nd }}$ permeation. It suggests that hydrogen atoms are additionally trapped at newly generated trapping sites under the loading condition even within the apparent elastic limit. Frappart et al. ${ }^{17}$ have indicated that the micro-plastic regions are generated under the tensile stress even within the elastic range, and the lattice distortion at the expanded interfacial gap between the matrix and precipitate provides trapping site for hydrogen atom. Since the high level of tensile stress can be concentrated at the incoherent region such as sharp edge or tip of the inclusion and precipitate, and the triaxial stress field can be set up in such regions, hydrogen atoms can be preferentially diffused and trapped at those sites. The HMT results conducted by Otsuka et al. ${ }^{41}$ and Yamada et al. ${ }^{42}$ can support these discussions. The microstructural heterogeneities caused by the tensile stress provide not only reversible trapping sites but also irreversible trapping sites. It suggests that both newly generated reversible and irreversible traps can contribute together to the slower diffusion rate and a little decrease in the value of $j_{s s}$ of the $2^{\text {nd }}$ permeation under local plasticity.

Fig. 7 also includes the $2^{\text {nd }}$ permeation curve of the steel under a load of $120 \%$ YS which belongs clearly to the generalized-plastic domain. Like the case of the local-plastic domain, the slower diffusion rate and a little decrease in $j_{s s}$ caused by the additional hydrogen trapping effect are clearly observed. In addition, the break-through time is much longer compared to the case of the local-plastic domain. The longer break-through time is mainly due to the hydrogen trapping effect by newly generated dislocation and micro-void under the plastic stress condition. The longer break-through time and slower permeation rate under the tensile stress in plastic range have also been discussed in our previous works. ${ }^{14-16}$ In general, under the generalized-plastic domain, applied stress can concentrate mostly at the $2^{\text {nd }}$ phase particles and hydrogen atoms can be preferentially trapped at those sites like the case of the local-plastic range. Garet et al. ${ }^{43}$ have reported that the plastic deformation is concentrated at the inclusion, leading to cracking in the bulk of the inclusion, either at the inclusion matrix interface or at sharp extremities. With the experimental result only, however, it is not possible to clearly understand this phenomenon and therefore the numerical curve-fitting method based on appropriate equation is required. It is discussed in more detail in the following section.

The reliability of the permeation data depends greatly upon the stability of the coating layer on the detection side of the steel membrane. ${ }^{14,15,44}$ Particularly, under the tensile stress condition, the thin layer of Pd coating deposited on the high strength steel membrane can be plastically deformed and damaged. It results in an unstable background current and unreliable permeation data in the permeation test and this can be clearly demonstrated in our previous works. ${ }^{14,15}$ For this reason, Pd coating cannot be applied for the experiment involving the stepwise sequence designed in this study. Instead of Pd, Ni-coating having much higher elongation level $(>10 \%)$ was used in this study since higher elongation level of the Ni-coating layer can endure higher level of loading condition. Although the efficiency of hydrogen oxidation on the Ni coating layer is a little lower than that on the Pd coating layer, $\mathrm{Ni}$ coating has also been widely utilized in the permeation test due to its effective catalytic activity on hydrogen oxidation. ${ }^{36,45,46,47}$ This catalytic activity on hydrogen oxidation of $\mathrm{Ni}$ having high elongation level make it possible to evaluate the hydrogen permeation behavior of the high strength steel under high level of tensile stress even in plastic range. Fig. 8 presents the morphology of Ni-coating layer after the permeation test under load and no load. This indicates that there are no pores or defects even under the load over $95 \%$ YS of the steel and therefore the permeation data obtained from this experiment is sufficiently reliable.

It is also interesting to see the fact that fine size of blisters are frequently observed on the steel surface in charging side after the $2^{\text {nd }}$ permeation test under the load over $95 \%$ of YS. It appears that the density of surface blister increased with increasing the applied stress from $95 \%$ to $120 \%$ of YS. The formation of surface blister means that some cracks are formed below the blisters and the experimental evidence of this phenomenon is shown in Fig. 9. Kim et al. ${ }^{29}$ have revealed that the blister crack nucleates at precipitates such as $\mathrm{Ti}-\mathrm{Nb}(\mathrm{C}, \mathrm{N})$ clusters or inclusion such as elongated MnS, like the case of typical HIC. Since it is believed that the crack can be the irreversible trapping site for hydrogen atoms, the formation of cracks during the permeation test suggests that the trap density for hydrogen atoms can be changed during the test. Therefore, under the loading conditions of generating the local plasticity and generalized-plasticity, the conventional model for hydrogen diffusion cannot be applied directly and new approaches are required. Therefore, a modified diffusion equation by taking into account this fact is introduced in the following section.

Theoretical analysis. - Conventional diffusion models. - It is generally known that diffusion of hydrogen atoms in the steel occurs through the tetrahedral interstitial sites at low temperatures. ${ }^{48}$ For an
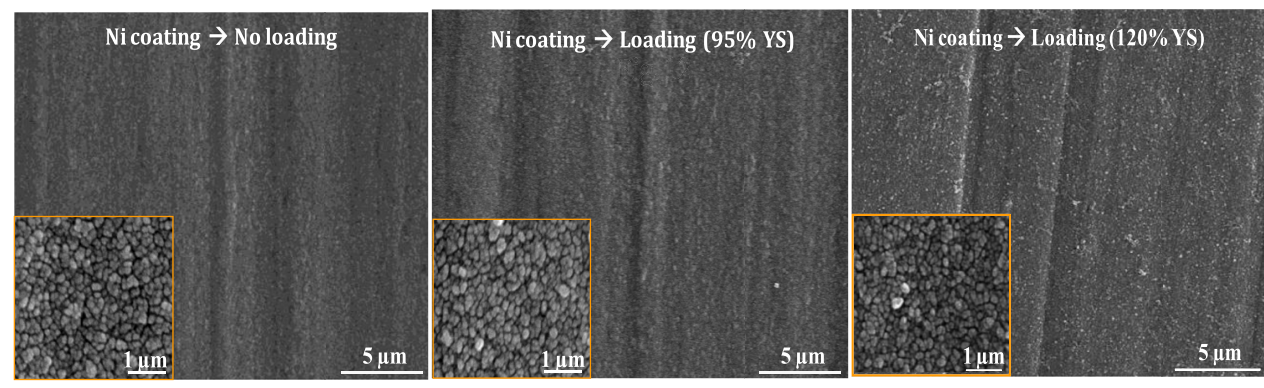

Figure 8. Surface morphology of Ni-coating layer on the tested steel under no loading condition, loading of $95 \%$ YS and $120 \%$ YS. 


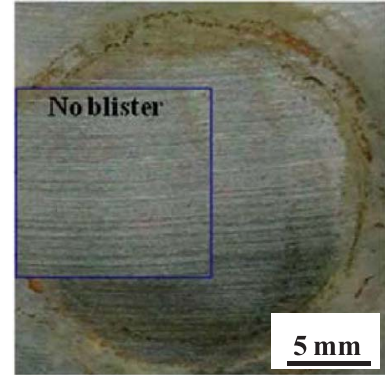

(a) Under no load

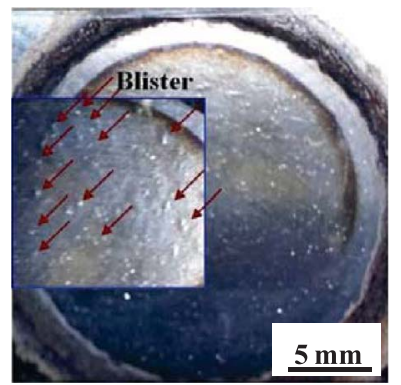

(c) Under load of $120 \%$ YS

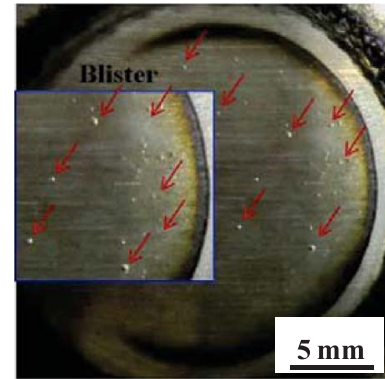

(b) Under load of $95 \%$ YS

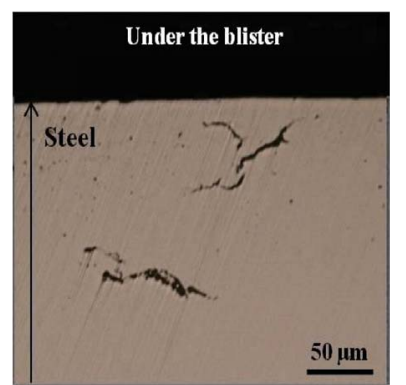

(d) Under load of $95 \%$ YS
Figure 9. Surface of the hydrogen charging side observed after $2^{\text {nd }}$ permeation under various load levels and the cracks developed under the surface blister observed on the cross-section after $2^{\text {nd }}$ permeation under load level of $95 \%$ YS.

ideal homogeneous material, the diffusion process can be described by the following Fick's second law with an assumption that the diffusion coefficient of hydrogen is independent of hydrogen concentration.

$$
\frac{\partial C(x, t)}{\partial t}=D \frac{\partial^{2} C(x, t)}{\partial x^{2}}
$$

where $D$ is the diffusion coefficient of hydrogen, $C(x, t)$ is the hydrogen concentration depending on the position, $x$, in the membrane and diffusion time, $t$. If the concentration of hydrogen atoms at the input side of the membrane keeps a constant value $\left(C_{0}\right)$ and the concentration at the output side keeps zero, the solution indicating the permeation transient is as follows:

$$
\frac{J_{\tau}}{J_{s s}}=1+2 \sum_{n=1}^{\infty}(-1)^{n} \exp \left(-n^{2} \pi^{2} \tau\right)
$$

where $J_{s s}$ is the steady-state permeation flux and $J_{\tau}$ is the time dependent flux. The dimensionless time parameter, $\tau$, is defined as $D t$ $l^{-2}$.

However, since most commercial steels contain a number of defects acting as trapping site for hydrogen atoms, the diffusion model should be modified. In the presence of reversible traps in the membrane, the governing equation for the distribution of hydrogen atoms can be expressed by:

$$
\frac{\partial C_{L}}{\partial t}=D_{L} \frac{\partial^{2} C_{L}}{\partial x^{2}}-N_{r} \frac{\partial \theta_{r}}{\partial t}=D_{L} \frac{\partial^{2} C_{L}}{\partial x^{2}}-N_{r}\left\{K_{r} C_{L}\left(1-\theta_{r}\right)-p \theta_{r}\right\}
$$

where $D_{L}$ is the lattice hydrogen diffusivity, $C_{L}$ is the lattice hydrogen concentration, $N_{r}$ is the reversible trap density, $\theta_{r}$ is the fractional occupancy of reversible traps, $K_{r}$ is the transition probability for hydrogen transport from lattice site to reversible trap and $p$ is the transition probability for hydrogen escape from the trap to lattice site. Oriani ${ }^{19}$ has indicated that the Eq. 4 can be simplified as follows only under the assumption of local equilibrium and negligible fraction of occupied traps.

$$
\frac{\partial C}{\partial t}=D_{a p p} \frac{\partial^{2} C}{\partial x^{2}}
$$

where

$$
C=C_{L}+C_{r}
$$

and

$$
D_{a p p}=\frac{D_{L}}{1+K_{r} N_{r}}
$$

where $D_{a p p}$ specifies the apparent hydrogen diffusivity and $C_{r}$ specifies the hydrogen concentration in reversible trap. With these conditions (i.e. under local equilibrium and low fraction of occupied trap), the analytical solution of the permeation buildup transient of Eq. 5 is expressed as follows:

$$
J_{H}=\frac{D_{a p p} C_{0}}{L}\left(1+2 \sum_{n=1}^{\infty}(-1)^{n} \exp \left[-n^{2} \pi^{2} \frac{D_{a p p} t}{L^{2}}\right]\right)
$$

where $J_{H}$ is the permeation transient and $C_{0}$ is the sub-surface hydrogen concentration at normal lattice sites plus reversible trap sites at the input side.

The governing equation with both reversible and irreversible trap sites in the membrane where no stress field is present has been proposed by Turnbull et al. ${ }^{22}$ and they define the irreversible traps with a finite trapping rate, not in local equilibrium. It can be expressed by:

$$
\frac{\partial C}{\partial t}=D_{L} \frac{\partial^{2} C_{L}}{\partial x^{2}}-N_{r} \frac{\partial \theta_{r}}{\partial t}-N_{i r r} \frac{\partial \theta_{i r r}}{\partial t}
$$

$$
\frac{\partial C}{\partial t}=D_{a p p} \frac{\partial^{2} C}{\partial x^{2}}-N_{i r r} \frac{\partial \theta_{i r r}}{\partial t}=D_{a p p} \frac{\partial^{2} C}{\partial x^{2}}-N_{i r r}\left\{K_{i r r} C\left(1-\theta_{i r r}\right)\right\}
$$

where $N_{i r r}$ is the irreversible trap density, $\theta_{i r r}$ is the fractional occupancy of irreversible traps and $K_{i r r}$ is the transition probability for hydrogen transport from lattice site to irreversible trap.

Turnbull et al. ${ }^{22}$ have proposed a numerical solution in the presence of irreversible traps with a finite trapping rate, not in local equilibrium. On the contrary, Castaño-Rivera et al. ${ }^{23}$ have proposed a numerical solution considering the case of local equilibrium and high fraction of high energy traps like irreversible traps but with no limitations in the trap filling rate. The calculation for the FDM proceeds from an initial condition in a succession of cycles and the numerical solutions of the Eq. $7 \mathrm{~b}$ is described as follow:

$$
C_{j}^{\prime}=C_{j}+D_{a p p} \frac{C_{j+1}+C_{j-1}-2 C_{j}}{(\Delta x)^{2}} \Delta t-N_{i r r} K_{i r r} C\left(1-\theta_{i r r}\right) \Delta t
$$

$$
\theta_{i r r}^{\prime}=\theta_{i r r}+K_{i r r} C\left(1-\theta_{i r r}\right) \Delta t
$$

where $C_{j}$ and $C_{j}{ }^{\prime}$ specify the number of diffusing atoms per unit volume at time, $t$ and at time, $t+\Delta t$, respectively, $\theta_{i r r}$ and $\theta_{\text {irr }}{ }^{\prime}$ specify the fraction of occupied traps at time, $t$ and at time, $t+\Delta t$, respectively, and $\Delta t$ is the time interval.

Curve-fitting to $1^{\text {st }}$ permeation curve.-The $1^{\text {st }}$ permeation involves both reversible and irreversible trapping phenomena, the permeation curves were fitted by Eq. 8. Basically, the curvet-fitting was conducted to minimize the deviation between the experimental and calculated data. This can be expressed as follows:

$$
\begin{gathered}
\operatorname{Min}\left[\sigma^{2}=\sum_{i}^{n} \frac{\left(j_{\exp }^{i}-j_{c a l}{ }^{i}\right)^{2}}{n}\right] \\
\frac{\partial \sigma^{2}}{\partial D_{a p p}}=0
\end{gathered}
$$




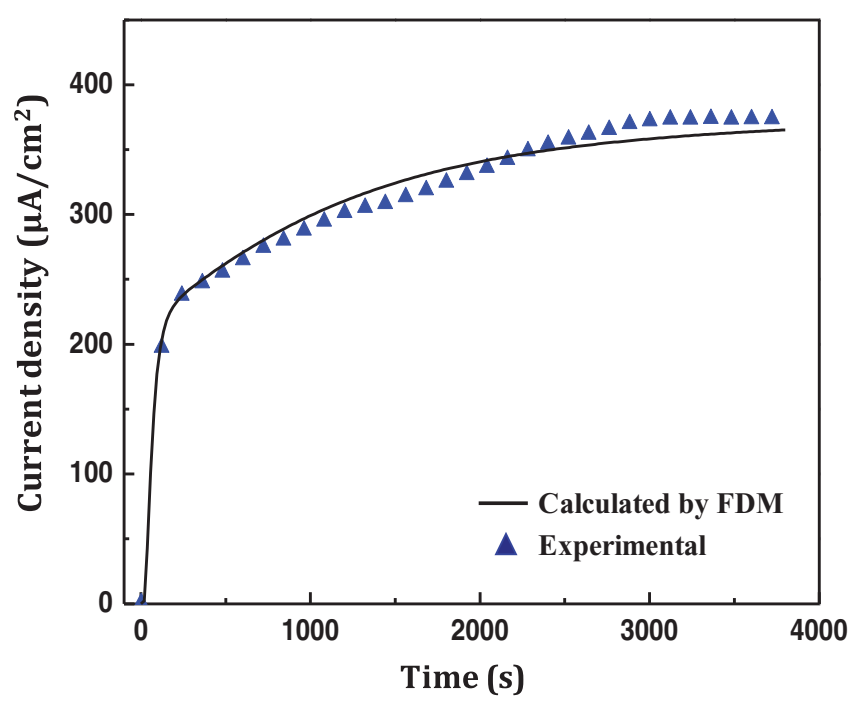

Figure 10. The curve-fitting to $1^{\text {st }}$ permeation data of the tested steels under no load.

where $j_{\text {exp }}$ and $j_{c a l}$ are the measured (experimental) and calculated permeation current density, respectively. $\mathrm{n}$ is the number of experimental data.

For simplicity, one assumption that only one type of irreversible trap site is present in the steel is made for this fitting method. With this assumption, the fitted curves and various fitted parameters are presented in Fig. 10 and Table I, respectively. As for the values of $K_{i r r}$ in the Table, comparing to the value of $K_{i r r}$ given in the study conducted by Turnbull, 22 it can be found that the capture rate constant obtained from the low carbon steel used in our study has lower value than that obtained from the martensitic stainless steel used in the study performed by Turnbull. Based on our simulation, in the low carbon steel exhibiting shorter break through time in $1^{\text {st }}$ permeation transient, the capture rate constant has smaller value than the case of the high alloy steels showing relatively longer break through time in the $1^{\text {st }}$ transient. Considering these facts, comparatively lower value of the kinetic constant obtained in the present study is mainly attributed to the shorter break through time in the permeation transient of the low carbon steel.

Curve-fitting to $2^{\text {nd }}$ permeation curve under elastic domain.-In order to understand the effect of tensile stress in generalized elastic range on hydrogen permeation, the $2^{\text {nd }}$ permeation curves under the loading condition of $80 \%$ YS and under no loading condition are compared by fitting the curves using Eq. 6. Since all of the irreversible traps are occupied during the $1^{\text {st }}$ permeation and only reversible traps are present in the $2^{\text {nd }}$ permeation, the curves are fitted by the Eq. 6 . This is shown in Fig. 11 indicating that the permeation flux $\left(J_{s s}\right)$ under the loading condition is higher than that under no loading condition. From the Eq. 6, it is found that the increase in permeation flux $\left(J_{H}\right)$ could be caused by the increase in apparent diffusivity $\left(D_{a p p}\right)$, subsurface hydrogen concentration $\left(C_{0}\right)$ and the decrease in the thickness of membrane. According to previous findings reported by some researchers, it is known that the tensile stress in elastic range does not affect the $D_{a p p} \cdot{ }^{10,12}$ In addition, the thickness of membrane under the stress in elastic range may be reduced marginally. Considering these facts, the increase in the permeation current under the stress condition is due mainly to the increase in sub-surface hydrogen concentration.

Table I. Diffusion parameters determined by curve-fitting to $1^{\text {st }}$ permeation under no load.

\begin{tabular}{cccc}
$D_{a p p}\left(\mathrm{~m}^{2} \mathrm{~s}^{-1}\right)$ & $K_{\text {irr }}\left(\mathrm{mol}^{-1} \mathrm{~m}^{3} \mathrm{~s}^{-1}\right)$ & $N_{\text {irr }}\left(\mathrm{mol} \mathrm{m}^{-3}\right)$ & $C_{0}\left(\mathrm{~mol} \mathrm{~m}^{-3}\right)$ \\
\hline $1.73 \times 10^{-9}$ & $1.35 \times 10^{-4}$ & 50.5 & 21.45
\end{tabular}

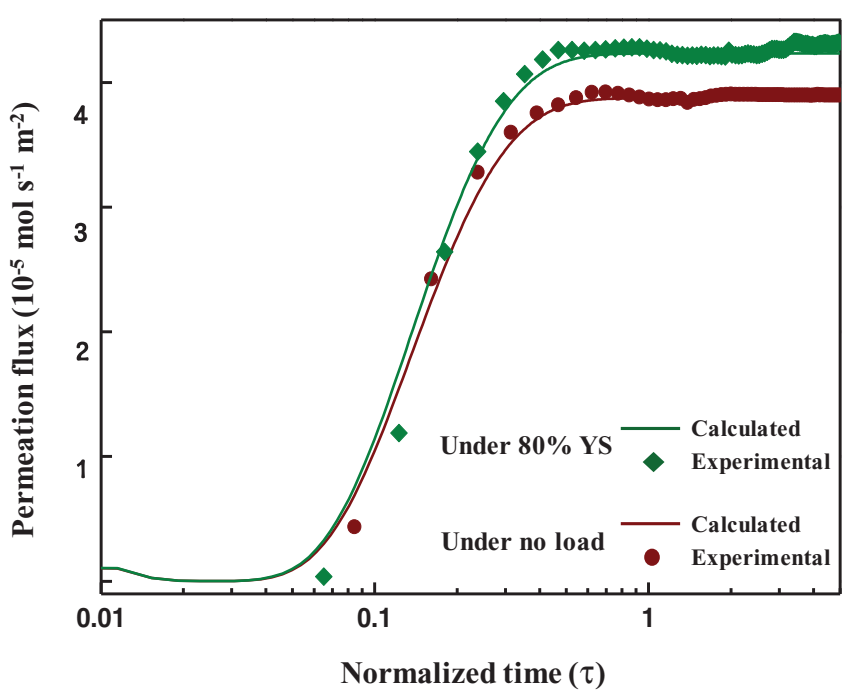

Figure 11. Comparison of the hydrogen permeation flux of $2^{\text {nd }}$ permeation between under load of $80 \%$ YS and no load.

This can be understood with the same context as the lattice expansion effect, suggesting that the steel can accommodate more hydrogen atoms interstitially under the tensile stress condition. ${ }^{10,12,13}$

Curve-fitting to $2^{\text {nd }}$ permeation curves under local/generalized plastic domain.-As pointed out in the previous section, under the loading condition generating local/generalized-plasticity, the conventional equations introduced previously cannot be applied directly due to the combined effect of the additional hydrogen trapping at expanded interfacial gap between the matrix and $2^{\text {nd }}$ phase particles, and formation of blister cracks. Therefore, a newly modified equation which takes into account the combined effect is proposed in this section. In spite of the $2^{\text {nd }}$ permeation, the high level of tensile stress generating the local/generalized plastic region creates new irreversible trap sites such as the expanded interfacial gap between the $2^{\text {nd }}$ phase particles and matrix, the micro-void and the blister crack as well as reversible trap sites such as dislocation and vacancy cluster. Particularly, the high level of tensile stress can be concentrated at the incoherent region such as sharp edge or tip of the $2^{\text {nd }}$ phase particles. In such regions, the triaxial stress field can be set up and hydrogen atoms can be preferentially diffused and trapped at those sites. For this reason, Eq. 8 is modified to accommodate these kinetic phenomena. In Eq. 8, the effect of reversible and irreversible trap is implicitly reflected on the value of $D_{a p p}$ and $N_{i r r}$, respectively. However, the value of $N_{i r r}$ determined by additionally applied stress is not constant but changes dynamically with the formation of internal cracks during the subsequent permeation. The governing equations and the numerical solutions for FDM under this condition is proposed as follows:

$$
\begin{array}{rr}
C^{\prime}=C+D_{a p p} \frac{C_{j+1}+C_{j-1}-2 C_{j}}{(\Delta x)^{2}} \Delta t-N_{\text {irr }}^{\text {total }} K_{\text {irr }} C\left(1-\theta_{\text {irr }}\right) \Delta t \\
N_{\text {irr }}^{\text {total }}=N_{\text {irr }}+\Delta N F_{\text {crack }}^{\text {blister }}
\end{array}
$$

where

$$
\begin{aligned}
F_{\text {crack }}^{\text {blister }} & =\frac{1}{1+\exp \left(-R\left(\theta_{i r r} N_{\text {irr }}-C_{\text {thres }}\right)+\ln (99.0)\right)} \\
\theta_{\text {irr }}{ }^{\prime} & =\left\{\theta_{\text {irr }}+K_{\text {irr }} C\left(1-\theta_{i r r}\right) \Delta t\right\} \times \frac{N_{\text {itr }}^{\text {total }}}{N_{\text {irr }}^{\text {tot }}}
\end{aligned}
$$

where $F_{\text {crack }}^{\text {blister }}$ specifies the fraction of newly generated blister crack induced by the generalized or local plasticity, which is in the range of 0 to $1, R$ specifies a parameter indicating how rapidly the crack formation proceeds and $C_{\text {thres }}$ specifies the hydrogen concentration 


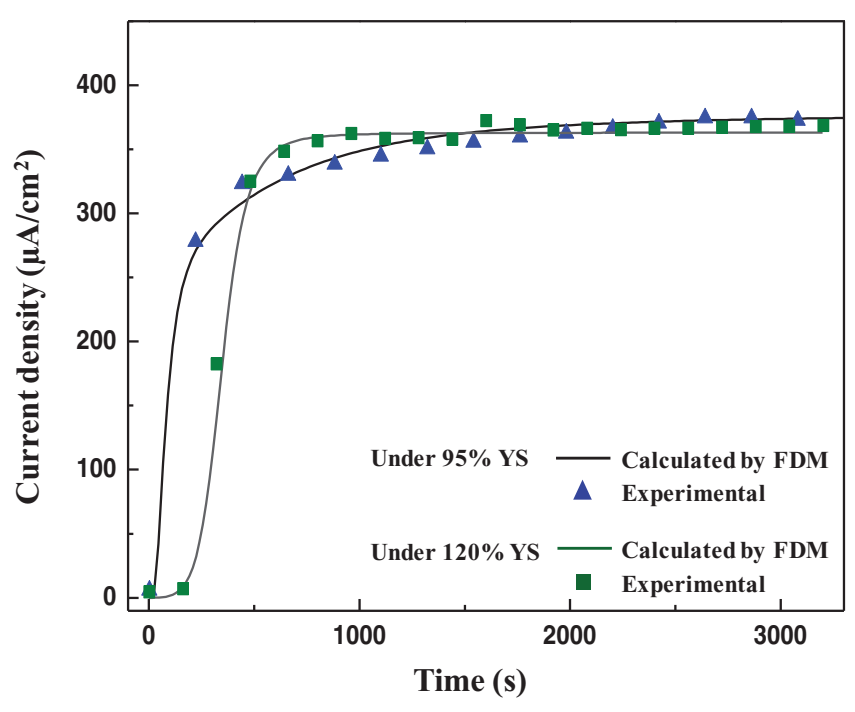

Figure 12. The curve-fitting to $2^{\text {nd }}$ permeation data of the tested steels under load of $95 \%$ and $120 \%$ YS.

when $F_{\text {crack }}^{\text {blister }}$ increases to $1 \%, N_{i r r}^{\text {total }}$ and $N_{i r r}^{\text {total }}$ specify the total number of irreversible traps at time $t$ and at time $t+\Delta t$, respectively, and $\Delta N$ refers the increased trap density as a result of crack formation. It is well known that the level of blister crack or HIC is highly dependent upon the hydrogen concentration in the steel. ${ }^{6,29}$ It is thus assumed that the density of blister crack increases with hydrogen content but reaches a steady-state after certain period of time as does the hydrogen permeation current otherwise it increases infinitely. The formation of crack in the steel matrix can therefore be expressed as the Eq. 10c. Simply, the parameter $F_{\text {crack }}^{\text {blister }}$ is a function of crack formation kinetics depending on hydrogen concentration. The value of $F_{\text {crack }}^{\text {blister }}$ can increase gradually in the range of 0 to 1 at the onset of hydrogen charging and loading. When the crack formation is completed under hydrogen charging and loading, newly generated irreversible trap density caused by the formation of blister crack is expressed as $\Delta N F_{\text {crack }}^{\text {blister }}$. Therefore, the total irreversible trap density, $N_{\text {irr }}^{\text {tot }}$ can be expressed by the sum of pre-existing irreversible trap density $\left(N_{i r r}\right)$ before hydrogen charging and newly generated trap density $\left(\Delta N F_{\text {crack }}^{\text {blister }}\right)$ during hydrogen charging and loading. This can be described as the Eq. 10 b.

Fig. 12 presents the curve-fitting based on the above equation and numerical solutions to the $2^{\text {nd }}$ permeation curve under the load of $95 \%$ and $120 \%$ YS. Various fitted parameters are listed in Table II. As indicated in the previous section, it is considered that only reversible trapping is involved in the $2^{\text {nd }}$ permeation under no load. However, the diffusion parameters such as $N_{i r r}$ and $\Delta N$ obtained under the load suggest that the irreversible trap site is newly formed under the stress condition. As expected, the apparent diffusion coefficient under the load of $120 \%$ is lower than that under the load of $95 \%$, which is attributed to the fact that the plastically deformed steel contains a considerable number of dislocations acting as reversible trapping site for hydrogen atoms. The applied tensile stress in both local and generalized plastic range affects not only the reversible trapping sites such as vacancy and dislocation, but also the irreversible trapping sites such as the expanded interfacial gap between the matrix and $2^{\text {nd }}$ phase particles, the micro-void and the blister crack. According to the internal pressure theory proposed by Zapffe and Sims, ${ }^{49}$ hydrogen trapping at the expanded interfacial gap under the plastic deformation favors the recombination of hydrogen and as a result, the cracks are locally created at the inclusion interface.

The values of $N_{i r r}$ and $K_{i r r}$ determined under the two load levels indicate that, with the transition of mechanical domain from local-plastic to generalized-plastic, a big increase in $K_{i r r}$ is observed, whereas there is no big difference in $N_{i r r}$. A big increase in the capture rate for hydrogen atoms from the interstitial lattice to irreversible trap sites suggests that the higher level of stress is concentrated at the sharp extremities of $2^{\text {nd }}$ phase particles, and facilitates the stress induced diffusion and trapping. In addition, the values of sub-surface hydrogen concentration $\left(C_{0}\right)$ and newly generated crack density $(\Delta N)$ under the generalized-plasticity are higher than those under the local-plasticity. Since $C_{0}$ is related to the hydrogen permeation flux at steady-state, it is logical that $\mathrm{C}_{0}$ increases as $D_{a p p}$ decreases as long as the steady-state flux remains practically constant, which is often observed after applying plastic deformation. However, an increase in the permeation flux at steady-state with increase in level of plastic deformation has also been reported by some researchers such as Huang and Tsuru, ${ }^{10}$ and Frankel and Latanision. ${ }^{50}$ They have also indicated that the active sites generated on a deformed surface act to enhance both the reduction of hydrogen ions and also the entry of hydrogen into the lattice. In addition, Hudson and Stragand, ${ }^{51}$ and Schumann and Erdmann-Jesnitzer ${ }^{52}$ have demonstrated similar results that the plastic deformation on the steel increased the hydrogen permeability up to $30 \%$ reduction, and further reduction lowered the permeability. Similarly, numerous researchers have reported that the effect of increasing plastic deformation is shown to increase the hydrogen concentration in the steel. ${ }^{53,54}$ Particularly, Townsend et al. ${ }^{55}$ has indicated that the increase in the hydrogen concentration is due to an increase in the exchange current density for hydrogen reduction reaction $\left(\mathrm{H}^{+}+\mathrm{e}^{-} \rightarrow \mathrm{H}\right)$ by lowering of the activation energy barrier for proton discharge as the bonds between metal atoms on the surface are stretched. However, experimental demonstrations of the phenomenon have not been provided. These mean that it is not yet clear whether the cathodic hydrogen evolution reaction can be increased with increase in plastic deformation or not. The only generally accepted fact is that the plastic deformation on the steel results in the decrease in $D_{a p p}$ and the increase in $C_{0}$. The formation of blister crack or cracking in the bulk of $2^{\text {nd }}$ phase particles under the generalized-plasticity may lead to increase the value of $\Delta N$ by providing additional trap site for hydrogen atoms.

It is generally known that the value of $C_{0}$ increases under plastic deformation, caused by the increase of the trapping sites under the stress condition. In addition, compared to the case under no load or elasticity, the thickness of the plastically deformed steel is smaller. Considering these facts and the following equation, Eq. 11, the plastically deformed steel can lead to an increase in $j_{s s}$. However, the increase of the trapping sites under the plastic deformation leads essentially to a decrease in apparent hydrogen diffusivity and therefore no big change in hydrogen flux at steady-state in spite of the change in trapping density under the loading condition is the generality.

$$
J=\frac{C_{0} D_{a p p}}{L}
$$

where $J$ is hydrogen permeation flux at steady-state, $C_{0}$ is sub-surface hydrogen concentration in lattice and reversible trap, $D_{a p p}$ is apparent hydrogen diffusivity and $L$ is steel thickness.

In the present study, the $j_{s s}$ measured under the generalizedplasticity showed a little lower value than those under other loading conditions as shown in Fig. 12. It may be caused by the decrease in $D_{a p p}$ under the generalized-plasticity. In addition, it is found from the

Table II. Diffusion parameters determined by curve-fitting to $2^{\text {nd }}$ permeation under load of $95 \%$ YS and $120 \%$ YS of the steel.

\begin{tabular}{lccccccc} 
& $D_{\text {app }}\left(\mathrm{m}^{2} \mathrm{~s}^{-1}\right)$ & $K_{\text {irr }}\left(\mathrm{mol}^{-1} \mathrm{~m}^{3} \mathrm{~s}^{-1}\right)$ & $N_{\text {irr }}\left(\mathrm{mol} \mathrm{m}^{-3}\right)$ & $\Delta N\left(\mathrm{~mol} \mathrm{~m}^{-3}\right)$ & $R$ & $C_{\text {thres }}\left(\mathrm{mol} \mathrm{m}^{-3}\right)$ & $C_{0}\left(\mathrm{~mol} \mathrm{~m}^{-3}\right)$ \\
\hline $95 \%$ YS & $1.43 \times 10^{-9}$ & $1.95 \times 10^{-4}$ & 18.96 & 12.4 & 4.5 & 24 \\
$120 \%$ YS & $1.19 \times 10^{-9}$ & $9.5 \times 10^{-3}$ & 18.92 & 30.5 & 7.9 & 26
\end{tabular}


result listed in Table II that, the tensile stress in generalized-plastic range leads to larger value of $R$. As indicated by the Eq. (10), the higher value of $R$ means faster crack formation rate, suggesting that the tensile stress in generalized-plastic range forms the blister crack more rapidly in the steel.

This study provides a new means to determine the hydrogen diffusion parameters for the high-strength steel subjected to the tensile stress even in plastic ranges. The numerical method used to solve the newly proposed diffusion equation makes it possible to determine the hydrogen diffusion parameters and trapping property by curve-fitting to the experimental data obtained under the plastic stress. It is believed that the current study will lead to understanding clearly of the SSC and delayed fracture of the high-strength steel under various applied stress conditions.

\section{Conclusions}

A numerical model is developed for determination of hydrogen diffusion parameters of the pressure vessel steel evaluated under tensile stress even in plastic ranges. In order to accommodate properly the effect of stress on the hydrogen permeation in the permeation equation, the electrochemical hydrogen permeation behavior is evaluated under generalized elasticity, local plasticity and generalized plasticity with a stepwise permeation sequence involving " 1 st permeation-desorption$2^{\text {nd }}$ permeation under loads." The major findings are summarized as follows:

1) From the fractography analysis of HIC and SSC, it is found that the cracks primarily nucleated at the enlarged $\mathrm{Ti}-\mathrm{Nb}(\mathrm{C}, \mathrm{N})$ and $\mathrm{Al}-\mathrm{Ca}-\mathrm{Mg}-\mathrm{O}$ cluster with size over 3 4 $\mu \mathrm{m}$. The failure mode of SSC for the steel is type I SSC which is generally termed as the stress-oriented hydrogen induced cracking (SOHIC).

2) The Ni coating used for catalyzing the oxidation of hydrogen at exit side does not show any fracture or defect after permeation test even under the plastic loading. The stable morphology of the $\mathrm{Ni}$ coating layer supports that the experimental permeation data obtained under various stress conditions are accurate and reliable.

3) The applied stress in generalized-elastic range ( $80 \%$ YS) leads to increase the steady-state permeation current density due to the elastically expanded lattice. It suggests that the steel can accommodate more hydrogen atoms interstitially under the elastic tensile stress.

4) Applied tensile stress belonging to local-plastic domain (95\% YS) results in slower diffusion rate and a little decrease in the steady-state permeation current density. By using the proposed diffusion equation, various diffusion parameters such as $N_{i r r}, K_{i r r}$ and $\Delta N$ are determined by curve-fitting. These values suggest that the irreversible trapping effect is involved in the steel under local plasticity.

5) The applied stress in generalized-plastic range (120\% YS) shows much longer break-through time and smaller value of $D_{a p p}$. It is due mainly to the fact that the plastically deformed steel contains a considerable number of both reversible and irreversible trapping sites for hydrogen atoms. With the transition of mechanical domain from local-plastic to generalized-plastic, a big increase in $K_{i r r}$ specifying the transition probability for hydrogen atoms from interstitial lattice to irreversible trap site is observed, whereas there is no big difference in $N_{i r r}$. In addition, the newly generated crack density $(\Delta N)$, sub-surface hydrogen concentration $\left(C_{0}\right)$ and crack formation rate $(R)$ under generalized-plasticity is higher than those under local-plasticity.

\section{References}

1. A. Brown and C. L. Jones, Corrosion, 40, 330 (1984).

2. H.-Y. Liou, R.-I. Shieh, F.-I. Wei, and S.-C. Wang, Corrosion, 49, 389 (1993).

3. S. U. Koh, J. S. Kim, B. Y. Yang, and K. Y. Kim, Corrosion, 60, 244 (2004).
4. A. Kawashuma, K. Hashimoto, and S. Shimodaira, Corrosion, 32, 321 (1976).

5. B. J. Berkowitz and F. H. Heubaum, Corrosion, 40, 240 (1984).

6. G. T. Park, S. U. Koh, H. G. Jung, and K. Y. Kim, Corrosion Science, 50, 1865 (2008)

7. C. Mendibide and T. Sourmail, Corrosion Science, 51, 2878 (2009).

8. J. Sojka, M. Jérôme, M. Sozańska, P. Váňová, L. Rytî́rová, and P. Jonšta, Materials Science and Engineering, A480, 237 (2008).

9. M. Kurkela, G. S. Frankel, and R. M. Latanision, Scripta Materialia, 16, 455 (1982).

10. Y. Huang, A. Nakajima, A. Nishikata, and T. Tsuru, ISIJ International, 43, 548 (2003).

11. A. M. Brass and J. Chêne, Corrosion Science, 48, 481 (2006).

12. W. Beck, J. O' M. Bockris, J. McBreen, and L. Nanis, R. Soc. 290, 220 (1966).

13. T. Zakroczymski, Corrosion, 41, 485 (1985).

14. S. J. Kim and K. Y. Kim, Scripta Materialia, 66, 1069 (2012).

15. S. J. Kim, H. G. Jung, and K. Y. Kim, Electrochimica Acta, 78, 139 (2012).

16. S. J. Kim, D. W. Yun, D. W. Suh, and K. Y. Kim, Electrochemistry Communications, 24, 112 (2012).

17. S. Frappart, X. Feaugas, J. Creus, F. Thebault, L. Delattre, and H. Marchebois, Materials Science and Engineering, A534, 384 (2012).

18. A. McNabb and P. K. Foster, Trans Metall. Soc. A.I.M.E. 227, 618 (1963).

19. R. A. Oriani, Acta Metallurgica, 18, 147 (1970).

20. M. Iino, Acta Metallurgica, 30, 367 (1982).

21. J. B. Leblond and D. Dubois, Acta Metallurgica, 31, 1459 (1983).

22. A. Turnbull, M. W. Carroll, and D. H. Ferriss, Acta Metallurgica, 37, 2039 (1989).

23. P. Castaño-Rivera, V. P. Ramunni, and P. Bruzzoni, Corrosion Science, 54, 106 (2012).

24. Evaluation of Pipeline and Pressure Vessel Steels for Resistance to Hydrogen-Induced Cracking, NACE standard TM0284, NACE International, Houston, TX (2003).

25. Laboratory Testing of Metals for Resistance to Sulfide Stress Cracking and Stress Corrosion Cracking in $\mathrm{H}_{2} \mathrm{~S}$ Environments, NACE standard TM0177, NACE International, Houston, TX (2005).

26. Standard Practice for Preparation and Use of Bent-Beam Stress-Corrosion Test Specimens, ASTM G39, ASTM International, Philadelphia, PA (2005).

27. T. Zakroczymski, Electrochimica Acta, 51, 2261 (2006).

28. NACE Task Group T-1F-23, Materials Performance, January, 58 (1993).

29. W. K. Kim, H. G. Jung, G. T. Park, S. U. Koh, and K. Y. Kim, Scripta Materialia, 62, 195 (2010).

30. A. Turnbull, M. Saenz de Santa Maria, and N. D. Thomas, Corrosion Science, 29, 89 (1989).

31. Method of Measurement of Hydrogen Permeation and Determination of Hydrogen Uptake and Transport in Metals by an Electrochemical Technique, ISO standard 17081, Switzerland (2004).

32. G. Benamati, A. Donato, A. Solina, R. Valentini, and S. Lanza, Journal of Nuclear Materials, 212, 1401 (1994).

33. N. Parvathavarthini, S. Saroja, and R. K. Dayal, Journal of Nuclear Materials, 264, 35 (1999).

34. S. L. I. Chan, H. L. Lee, and J. R. Yang, Metallurgical Transactions, 22A, 2579 (1991).

35. A. J. Kumnick and H. H. Johnson, Metallurgical Transactions, 5, 1199 (1974).

36. M. Hashimoto and R. M. Latanision, Metallurgical Transactions, 19A, 2789 (1988).

37. W. K. Kim, S. U. Koh, B. Y. Yang, and K. Y. Kim, Corrosion Science, 50, 3336 (2008).

38. A. J. Kumnick and H. H. Johnson, Metallurgical Transactions, 5, 1199 (1974).

39. J. L. Lee and J. Y. Lee, Metal Science, 17, 426 (1983).

40. H. G. Lee and J. Y. Lee, Acta Metallurgica, 32, 131 (1984).

41. T. Otsuka, H. Hanada, H. Nakashima, K. Sakamoto, M. Hayakawa, K. Hashizume, and M. Sugisaki, Fusion Science and Technology, 48, 708 (2005).

42. H. Yamada, M. Tsurudome, Y. Asano, N. Ogasawara, and K. Horikawa, Visualization of Hydrogen Evolution During Fatigue Deformation in 7075 Aluminum Alloy, in $7^{\text {th }}$ ISEM, International Symposium on Advanced Science and Technology in Experimental Mechanics, Taipei, Taiwan (2012).

43. M. Garet, A. M. Brass, C. Haut, and F. Guttierez-Solana, Corrosion Science, 40, 1073 (1998).

44. G. T. Park, H. G. Jung, S. U. Koh, and K. Y. Kim, Hydrogen Diffusion and Trapping Behavior of Linepipe Steel under Dead Weight Test Condition, in ISOPE 2009, p. 268, International society of ISOPE, Osaka, Japan (2009).

45. H. Ling, Research on Catalytical Properties on Coatings of Hydrogen Permeation Sensor, Master theses, Wuhan Univ. of Sci. and Eng, Wuhan, China (2011).

46. E. Akiyama, K. Matsukado, S. Li, and K. Tsuzaki, Applied Surface Science, 257, 8275 (2001)

47. S. H. Wang, W. C. Luu, K. F. Ho, and J. K. Wu, Materials Chemistry and Physics, 77, 447 (2002).

48. K. Kiuchi and R. B. Mclellan, Acta Metallurgica, 31, 961 (1983).

49. C. Zapffe and C. Sims, Trans. AIME 145, 225 (1941).

50. G. S. Frankel and R. M. Latanision, Metallrugical Transactions, 17A, 869 (1986).

51. R. M. Hudson, K. J. Riedy, and G. L. Stragand, Corrosion, 17, 334 (1961).

52. H. Schumann and F. Erdmann-Jesnitzer, Arch. Eisenhuttenw, 24, 353 (1953).

53. R. M. Hudson, K. J. Riedy, and G. L. Stragand, Corrosion, 17, 86 (1961)

54. J. H. Keeler and H. M. Davis, Trans. AIME, 197, 44 (1953).

55. H. E. Townsend, Corrosion, 26, 361 (1970). 